LA W RENCE LIVERMORE NATIONAL LABORATORY

PRP Review of shots beyond FY14 Q1/Q2 Report

M. D. Rosen

February 12, 2014 
This document was prepared as an account of work sponsored by an agency of the United States government. Neither the United States government nor Lawrence Livermore National Security, LLC, nor any of their employees makes any warranty, expressed or implied, or assumes any legal liability or responsibility for the accuracy, completeness, or usefulness of any information, apparatus, product, or process disclosed, or represents that its use would not infringe privately owned rights. Reference herein to any specific commercial product, process, or service by trade name, trademark, manufacturer, or otherwise does not necessarily constitute or imply its endorsement, recommendation, or favoring by the United States government or Lawrence Livermore National Security, LLC. The views and opinions of authors expressed herein do not necessarily state or reflect those of the United States government or Lawrence Livermore National Security, LLC, and shall not be used for advertising or product endorsement purposes.

This work performed under the auspices of the U.S. Department of Energy by Lawrence Livermore National Laboratory under Contract DE-AC52-07NA27344. 


\section{PRP Review of shots beyond FY14 Q1/Q2 Report}

\section{Introduction:}

Document \#: LLNL-XXxxxx-DRAFT

On February 4, 2013 the Peer Review Panel, as part of the NIF Governance plan, met along with the HED and ICF councils, to review 7 campaigns that were additional to (or expanded from) those considered since the June 2013 PRP review of the proposed shots that had been planned for Q1 and Q2 of FY14 (and beyond). We summarize here our findings, followed by a paragraph of details on each of the 7 campaigns we reviewed. In many cases the panel's recommendations are unanimous or nearly so, as delineated in the detailed paragraphs. In at least one case (High Z) the panel was far from unanimous. This being our first "joint meeting with the councils", we include remarks about the review process itself.

\section{Part A: Overview of Findings:}

The new paradigm, to be implemented, in part, onto NIF, of mini-campaigns to improve shot rate etc. has led to a great burst of creativity and enthusiasm amongst the scientific staff. Moreover, the possibility is high that such enthusiasm will be rewarded with actual experiments. We applaud this development.

ICF and HED program leaders, as well the NIF Director, have much to be proud of. These campaigns continue to produce valuable data ( $\&$ design challenges) which will:

- Contribute to achieving program goals

- Produce valuable applied science discoveries

- Excite and vitalize the work-force

- Train students and post docs as well.

We applaud the effort to have the HED and ICF councils meet jointly. We look forward to venue leading to more cross fertilization of ideas. An excellent example would be the HDC capsules in Near Vacuum Hohlraums (NVH) of ICF, and the current plans for the HED 2-shock operating in a NVH. Symmetry issues could be jointly tackled.

This particular meeting was an "experiment" in having PRP/FRC and the HED/ICF councils jointly review the proposals, in part, as an attempt to lower the number of reviews the PIs must give. It led to some lack of clarity of lines of responsibility, which should be evaluated before the next meeting.

\section{Evaluation:}

The 7 campaigns tiered into 3 categories (based on the scoring criteria), with (B) being only slightly below (A), and (C) decidedly below (B):

(A). Menkar, High Z, Polar Direct Drive

(B). 2-shock, Be-capsules, Cu-lined Hohlraums

(C). Cepheus 
More "lessons learned" path forward for our PRP review process:

The proposal template had a collection of "9 questions" to be answered. Some of the presentations responded quite clearly and directly to them, which we greatly appreciate. We would hope that all future proposals have a rigorous adherence to that model, possibly through a paragraph or two of prose it that's easier. We would also prefer to have the proposals available to us earlier in the process.

\section{Part B: Detailed Report, by Campaign:}

\section{Be-capsules:}

The panel believes that Be is worth pursuing as an alternate ablator material. However, the shot plan presented is inadequate for the stated goal of being on a near equal footing with $\mathrm{CH}$ capsules by the end of FY15, and seems predicated on anticipated success at each step. As such, the campaign as proposed is unlikely to meet its stated goals. Either lower the goal to be that of simply producing solid results, or more shots and more time are required. Comparison with the high foot campaign's history suggests that the team should plan on more conAs, at least one symcap, and a few HGR experiments and perform the associated design studies. The panel would have appreciated more discussion of target fabrication issues. The effort is likely to need the committed involvement of LLNL hohlraum engineering/LPI experts. The team is otherwise strong. It is clear the NIF is the only facility for this work and that high energy/power shots are required.

Action items:

Either upgrade the shot request (including DU hohlraums) or downgrade the stated goals.

If more shots are to be requested perform the necessary design studies. In particular the HGR platgfrom may need a different backlighter.

\section{Cu lined hohlraums:}

The panel believes that $\mathrm{Cu}$ lined hohlraums is worth pursuing as an exploration into the tool kit of hohlraum modifications / improvements. The questions as to whether $\mathrm{M}$ band are a source of low mode asymmetry or seeds for hydro instability can thus be explored, as well as allowing for targets with less dopants. The SBS mitigation techniques will be of value to any hohlraum that has the desired less CBET, smaller delta-lambda, and thus brighter outer beams that can lead to SBS. DU hohlraums should also be explored in the same vein. Target fabrication needs to explore pure DU, and a time dependent SXI could help assess the $\mathrm{Cu}$ bubble vs time evolution. Possibly use Omega to test $\mathrm{Cu}$ laser-burn-thru-thickness. The team should be augmented by atomic physics expertise.

Action items:

Target fabrication to explore pure DU hohlraum 
The facility should bring up a time dependent SXI

The use of Omega should be considered for measuring the laser burn-thru of $\mathrm{Cu}$ thickness.

The team should be augmented by atomic physics expertise.

\section{Polar Direct Drive (PDD) Implosions:}

The panel agrees that the planned backlighting experiments for the PDD campaign are the highest priority. Resolving the radius versus time measurement discrepancy with the simulations is important and should be done prior to a CBET study. There are questions about the observables in the CBET experiments. It would help to clarify how the effect of CBET will be quantified. If either implosion symmetry or shell radius versus time are the metrics, then the idea to repoint one hemisphere's beams to mimic hemispheric wavelength control may not give sufficiently uniform drive to the capsule. The group is encouraged to be more aggressive on the implementation of hemispheric delta lambda? The alternate ablator campaign is of lower priority and should be reconsidered after the OMEGA experiments. This is an experienced group of researchers and should be able to accomplish the goals of the experiments, but it is not clear that an expanded shot schedule can be supported with the team in place.

Action items:

Make backlighting a priority

Clarify the observables when delta lambda is deployed, especially with regard to symmetry issue

Pursue hemispheric delta lambda capability

\section{High Z:}

There is a consensus that NIF should get high $\mathrm{Z}$ data; There my be a disagreement on time scale. Both approaches have technical issues. Given those issues, there is disagreement on the panel as to the best approach to addressing them. Some believe that the technical issues can be overcome. The large effort is warranted because of the importance of the experiments. Others believe that the effort is diluted by maintaining both approaches. The down select should thus be done early to focus effort on one approach to better assure success and to make the shot load more manageable. The team should be expanded to include external collaborators to expand its technical base. There should possibly be more design effort to expand the approach and have more innovation.

Given the diversity of opinion on the panel we are loath to communicate explicit action items.

\section{2 shock experiments:}

The panel had a range of opinions on the necessity of adhering closely to scaling methodology in order to meet the objectives. All thought the experiments should move quickly to lower energy scales, perhaps as low as $800 \mathrm{~kJ}$. There is concern 
that the long pulse combined with a near vacuum hohlraum could lead to large symmetry swings, so the team should consider a gas filled option. The committee saw value in scanning both symmetry and convergence ratio. It may prove difficult, however, to interpret data from combining a convergence ratio scan with the $\mathrm{CD}$ mix cap technique. The mix experiments might be best at fixed convergence ratio, but calculations indicating they would have sufficient sensitivity are also needed. Complementary mix measurements, e.g. with spectroscopic tracers, would strengthen the case for the mix experiments. Involvement of more experimentalists would help, along with collaboration with LANL and AWE scientists working on similar things.

Action items:

Explore moving to a lower energy scale mini campaign platform.

Explore gas filled hohlraum if symmetry control in the NVHs prove challenging. Seek greater involvement of LANL and AWE colleagues.

\section{Cepheus:}

The short-term aim of Cepheus is to provide data to examine outstanding discrepancies between the existing Pleiades rad flow data set and modeling. This involves further hohlraum drive measurements and foam EOS and opacity characterization (at different density). The longer-term aim is to examine a radhydro issue of current interest, and this will benefit from the earlier Cepheus/Pleiades characterization work. The panel thought that Cepheus should not be considered for scheduling at this time. The short-term characterization component was considered worthwhile but more detailed designs are required including a fuller assessment of required and achievable measurement accuracies. Additional measurements such as ionization state to constrain the foam EOS/opacity and radiographic imaging of the tube evolution should be considered, and whether Omega or Z could be used for some of this work. The longer-term rad hydro proposal was considered too immature, with insufficient thought given to whether this was in a relevant regime with radiation playing the required role. Detailed inter-lab code-code comparisons should be explored on this issue before starting an experimental study. In addition, previous NIF, Omega, etc. experiments may have already probed similar efforts. Overall, Cepheus has strong team of experimental experiments, but was lacking in design effort at this time.

Action item

Return next time with clearer designs

\section{Menkar:}

The panel recognized that this experiment will contribute important data in a key programmatic area. As with several other experiments, this is an integrated test of code modeling. The experiment builds on much preparatory work, including a large number of NIF shots, in an attempt to constrain uncertainty. The panel was impressed by the high quality of the experimental design presented, in terms of the very detailed consideration of errors and uncertainties. It was recognized that a key 
assertion is that calibrations carry across from one configuration to another. One panel member thought that this assertion was questionable, whilst most of the panel was satisfied that evidence presented from simulations adequately supported this assertion. There is a strong design and experimental team, with a proven record of delivery, and a preliminary shot in this campaign has already been successful. Only NIF provides the conditions and precision to perform these experiments.

Action item:

Continue the experiments.

\section{Acknowledgements:}

In closing we thank Chris Keane of the NIF User office and his excellent staff for their excellent guidance, and logistical support for this challenging joint councils/PRP Review. They rose nobly to the challenge, and the day ran remarkably smoothly. We thank Warren Hsing, and the entire FRC team of reviewers for providing us with expert opinion on Facility Readiness issues.

Disclaimer:

This document was prepared as an account of work sponsored by an agency of the United States government. Neither the United States government nor Lawrence Livermore National Security, LLC, nor any of their employees makes any warranty, expressed or implied, or assumes any legal liability or responsibility for the accuracy, completeness, or usefulness of any information, apparatus, product, or process disclosed, or represents that its use would not infringe privately owned rights. Reference herein to any specific commercial product, process, or service by trade name, trademark, manufacturer, or otherwise does not necessarily constitute or imply its endorsement, recommendation, or favoring by the United States government or Lawrence Livermore National Security, LLC. The views and opinions of authors expressed herein do not necessarily state or reflect those of the United States government or Lawrence Livermore National Security, LLC, and shall not be used for advertising or product endorsement purposes.

This work performed under the auspices of the U.S. Department of Energy by Lawrence Livermore National Laboratory under Contract DE-AC52-07NA27344

Submitted: February 5, 2014

Mordecai D. ("Mordy") Rosen, LLNL, - Chair

Warren Garbett, AWE

Peter Graham, AWE

Jim Hammer, LLNL

Don Haynes, LANL

Bob Kauffman, LLNL

Jim Knauer, URLLE

Document \#: LLNL-xxxxxx-DRAFT 